\title{
The incidence of coeliac disease and early weaning
}

The estimated incidence of coeliac disease in children in Britain varies from $1: 1850^{1}$ to $1: 1100,{ }^{2}$ but a decline in the disorder between 1974 and 1979 has been reported from three regions. ${ }^{3-5}$ This finding may be related to changes in infant feeding practices recommended by the DHSS report Present day practice in infant feeding (1974). ${ }^{6}$ One such recommendation discouraged both the early introduction of cereals and other solid food into the diet of babies before age 4 months and the addition of cereal foods in any form to the milk in the bottle feed. These suggestions were prompted by a trend towards the early introduction of cereals into the infant's diet that occurred in the 1960s and early 1970s which was associated with a progressive fall in the mean age of presentation of coeliac disease in some centres. ${ }^{2} \mathrm{~A}$ study on infant feeding in $1975^{7}$ reported that $85 \%$ of babies had been given solids by age 3 months, but by 1980 this figure had fallen to $55 \%$ in England and Wales. ${ }^{8}$ As cereals and rusks are traditionally the first weaning foods used in infancy and gluten-free varieties of these foods have been increasingly promoted, both solids and gluten have been introduced progressively later.

Before the declining incidence of coeliac disease can be attributed to a delay in the introduction of gluten into the infant's diet, re-examination of the evidence linking early weaning with an increased incidence of coeliac disease before 1974 is necessary. A study of the records from the Royal Hospital for Sick Children, Glasgow between 1950 and 1973 concluded that increased numbers of patients with coeliac disease were admitted between 1958 and 1965 and between 1966 and 1973 than between 1950 and $1957 .{ }^{6}$ Cereals were also introduced at an increasingly earlier age during the first two periods, and in 1965 gluten-containing foods were being given to $91 \%$ of Glasgow children before age 3 months. ${ }^{9}$ However since 1970 the criteria for the diagnosis of coeliac disease have been more clearly defined following a report from the European Society for Paediatric Gastroenterology.

Before this report the diagnosis was sometimes made on clinical grounds alone, without a small intestinal biopsy and gluten challenge was seldom performed to establish the permanence of the disorder. It is likely that some earlier population studies on coeliac disease may therefore have included patients with temporary gluten intolerance and perhaps some with other gastrointestinal disorders-such as the post-enteritis syndrome.
Early weaning with gluten-containing foods cannot therefore be related directly to an increased incidence of coeliac disease on the current evidence.

Although delay in the introduction of gluten into the infant's diet has been suggested as an explanation for the declining incidence of coeliac disease, it is possible that the onset of symptoms may only have been postponed until later on in childhood, or until adulthood. Alternatively other important changes in infant feeding practices that could also influence the incidence of coeliac disease have occurred since the mid-1970s, such as an increase in breast feeding. A reduction in the number of children with gastroenteritis, ${ }^{10}$ delay in the onset of feeding with cows' milk protein, and the treatment of early symptoms of coeliac disease with elimination diets without reference to a paediatrician, are other factors that may contribute to the apparent decline in the incidence of childhood coeliac disease in Britain.

\section{References}

1 McCrae W M. Inheritance of coeliac disease. J Med Genet 1969; 6: 129-31.

2 McNeish A S, Anderson C M. Coeliac disease: the disorder in childhood. In: Cooke W T, Asquith P, eds. Clinics in gastroenterology. Vol. 3, No 1. London: Saunders, 1974: 127-44.

3 Littlewood J M, Crollick A J, Richards I D G. Letter: Childhood coeliac disease is disappearing. Lancet 1980; ii: 1359 .

4 Challacombe D N, Baylis J M. Letter: Childhood coeliac disease is disappearing. Lancet 1980; ii: 1360.

5 Dossetor J F B, Gibson A A M, McNeish A S. Letter: Childhood coeliac disease is disappearing. Lancet 1981; i: $322-3$.

- Panel on Child Nutrition Working Party on Infant Feeding. Present-day practice in infant feeding. Report on Health and Social Subjects No 9. London: HMSO, 1974: 24-6.

7 Martin J. Infant feeding 1975: attitudes and practice in England and Wales. London. HMSO, 1978: 99-108.

8 Martin J, Monk J. Infant feeding 1980. London: OPCS, 1982: 46-50.

9 Arneil G C. Dietary study of 4365 Scottish infants- 1965. Scottish Health Service Studies No 6. Edinburgh. HMSO, 1967: 89.

10 Wharton B A. Past achievements and future priorities-a view of present-day practice in infant feeding 1980 . In: Turner M R, ed. Nutrition and health-a perspective. Lancaster: MTP Press, 1982: 169-81.

D N Challacombe The Somerset Children's Research Unit, Taunton and Somerset Hospital, Musgrove Park, Taunton, Somerset 